\title{
Poland Syndrome with Unilateral Vocal Fold Paralysis
}

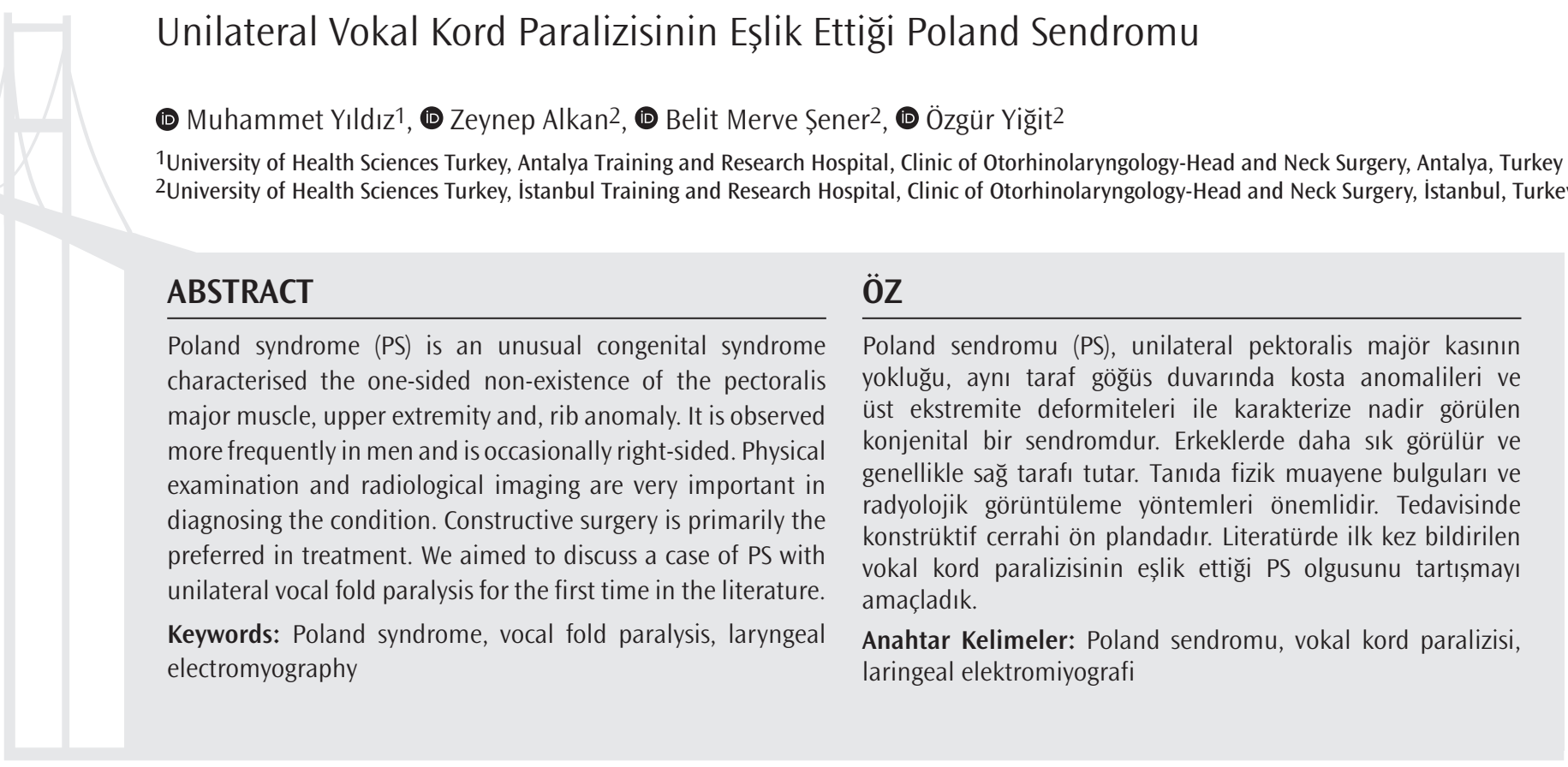

\section{Introduction}

Poland syndrome (PS) is an uncommon constitutional abnormality, which is typically described as the unilateral non-existence of the pectoralis major muscle; non-existence of the breast and nipple; lack of the pectoralis minor muscle; anomalies of the anterior ribs, scapula and clavicle; alopecia of the axillary and mammary regions; brachydactyly and syndactyly $(1,2)$. It occurs more frequently in men and on the right side (3). Physical examination and radiological imaging are important in making the diagnosis. In this paper, we present a rare case of PS with unilateral vocal fold paralysis and also discuss the results in the literature.

\section{Case Report}

A 58-year-old male patient suffering from dysphonia presented to our clinic. In the meantime, a right-sided chest depression was present. He had been suffering from long-term dysphonia since childhood, and had no history of surgery. On physical examination, we observed the right hemithorax depression, the non-existence of the pectoral muscles (Figure 1) and that the right nipple was upper-situated than the left nipple. Other clinical and laboratory results were within the normal range. There was no family history of laryngeal diseases. A chest radiograph showed hyperlucency of the right hemithorax, and the heart substituted left hemithorax was observed; upon this knowledge, a thorax computed tomography (CT) was planned. In thorax $\mathrm{CT}$, the non-existence of the pectoralis major muscle, $3^{\text {rd }}$ costal hypoplasia, and decreased attenuation of the right lung were observed (Figure 2). The right lattisimus dorsi and serratus anterior muscles were found to be normal. Cranial and neck CT performed to investigate the aetiology of the vocal fold paralysis were normal and did not yield any pathological result. Abdominal ultrasonography, breath function test, and cardiac electrocardiography-echography were also normal. On stroboscopic examination for the vocal fold paralysis, it was observed that the left-side vocal fold found in the paramedian position while the left arytenoid was displaced towards the inferomedial position (Figure 3). In laryngeal electromyography (EMG), no motor unit potentials were seen in the thyroarytenoid and cricothyroid muscles. The neural damage and denervation potentials were recorded in the laryngeal EMG. Due to the patient's request, reconstructive surgery was not performed; the patient was informed about his vocal fold pathology and recommended followups with breath and voice exercise programmes. Approval (informed consent) was obtained from the patient to present this case report.
Address for Correspondence/Yazıșma Adresi: Muhammet Yıldız MD, University of Health Sciences Turkey, Antalya Training and Research Hospital, Clinic of Otorhinolaryngology-Head and Neck Surgery, Antalya, Turkey Phone: +90 5063698860 E-mail: dr_yildiz_muhammet@hotmail.com ORCID ID: orcid.org/0000-0002-1771-7345

Cite this article as/Atıf: Yıldız M, Alkan Z, Șener BM, Yiğit Ö. Poland Syndrome with Unilateral Vocal Fold Paralysis. İstanbul Med J 2020; 21(Suppl 1): 28-31.
Received/Geliș Tarihi: 07.05.2020 Accepted/Kabul Tarihi: 13.08 .2020

(C) Copyright 2020 by the University of Health Sciences Turkey, Istanbul Training and Research Hospital/istanbul Medical Journal published by Galenos Publishing House.

(C) Telif Hakkı 2020 Sağlık Bilimleri Üniversitesi Istanbul Ĕgitim ve Araştırma Hastanesi/Istanbul Tıp Dergisi, Galenos Yayınevi tarafından basılmıștır. 


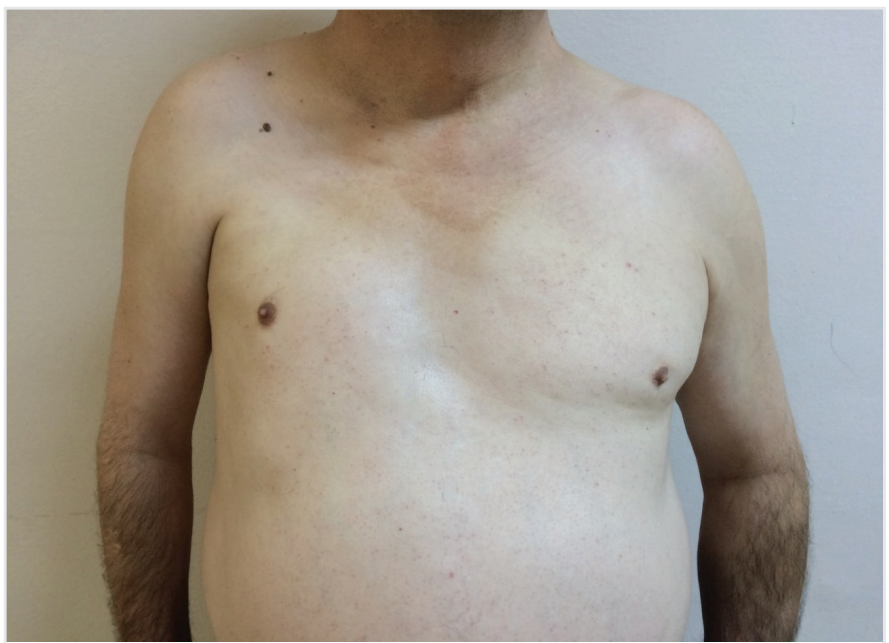

Figure 1. Chest asymmetry with right anterior chest wall depression and an absent pectoralis muscle

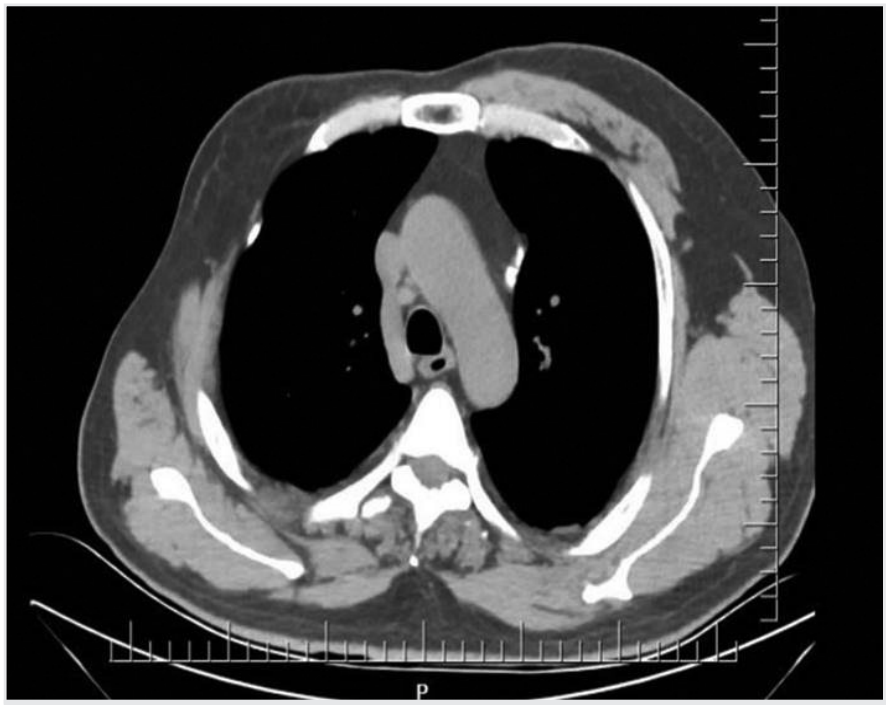

Figure 2. Thorax computed tomography of the axial plane shows the absence of the pectoral muscles in the right side

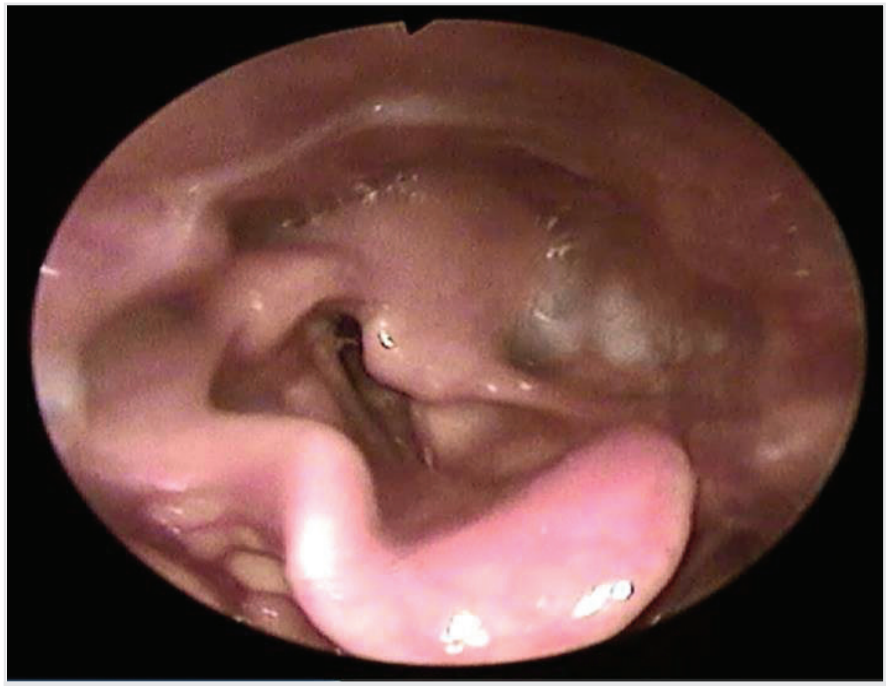

Figure 3. Endoscopic image of the left vocal cord paralysis

\section{Discussion}

PS is an unusual congenital abnormality that is defined as a onesided thoracic development disorder (4). The non-existence of the unilateral pectoralis major muscle is the main pathological condition, and underdevelopment or non-existence of the breast and nipples often accompanies this anomaly. In addition, this syndrome may be accompanied by non-existence of the pectoralis minor muscle; deformities of the scapula, clavicle and rib; and alopecia of the axillary and mammary region. Less frequently, the latissimus dorsi, serratus anterior and external oblique muscles may also be involved $(5,6)$. The hypoplasia of the forearm, wrist, or hand, brachydactyly and non-existence of the phalanges or digits can be seen as extremity abnormalities (7). Breast abnormalities may range from breast absence to simple breast hypoplasia (8). Our patient has non-existence of the right pectoralis major-minor muscles and third rib hypoplasia.

The incidence of PS ranges from $1 / 7,000$ to $1 / 100,000$ (9). PS is more common in men. It mostly affects the right side of the body and bilateral involvement is extremely rare (10). The most accepted theory is that in the sixth-seventh week of embryonic life, blood flow decreases on the affected side as a result of the abnormality of the subclavian or vertebral arteries or their branches, and this situation causes partial tissue loss in the affected region (11). Another hypothesis is that various factors like congenital vascular maldevelopment, injuries and exposure to medications in the intrauterine period may lead to hypoxia in the chest wall and adjacent extremity bud of the foetus and finally result in this syndrome $(12,13)$. PS is generally considered to be a sporadic congenital anomaly, but hereditary cases have been reported (14). In our case, there was no hereditary factor and a right side involvement in accordance with the existing literature.

PS may be accompanied by various visceral abnormalities and neoplasms; therefore, it is important to be diagnosed. Diagnosis is made by physical examination and radiological imaging. Chest deformity, organ growth retardation and limb anomalies can be detected during the physical examination. Chest radiography may show that, radiolucency is observed to increase, and displaced to the other side of the heart. The extremity radiography may demonstrate hand anomalies. CT imaging can show muscle and bone anomalies in detail, thus providing useful data for planning a reconstructive surgery (15). In our case, the nonexistence of the right pectoralis major muscle, $3^{\text {rd }}$ costal hypoplasia and decreased attenuation of the right lung were observed in thorax CT.

PS is less often accompanied by other abnormalities such as renal anomalies, endocrine anomalies, dextrocardia, Sprengel deformity, Myasthenia gravis, Mobius syndrome and Parry Romberg syndrome (16). Interrelation was found with leukaemia, Iymphoma, leiomyosarcoma, breast tumour and neuroblastoma, demanding heightened oncological awareness in these settings (17-19). In our case, we did not detect any symptoms related to those diseases or syndrome.

Vocal fold paralysis is frequently detected in otolaryngology practice. Although the aetiology of paralysis is variable, iatrogenic trauma, malignant tumours and infections have been commonly reported as being the cause $(20,21)$. However, a cause may not be detected in approximately $20 \%$ of patients. The most common cause of paralysis 
has been reported as surgical trauma (22). Additional findings of our patients were not available to explain the aetiology of the vocal fold paralysis.

Videolaryngoscopy is widely used as a diagnostic tool in the management of vocal fold paralysis (23). Laryngeal EMG is often used to predict the diagnosis, pathogenesis and prognosis of vocal fold paralysis (24). In patients whose paralysis has not improved, compensation mechanisms are developed to maintain the natural structure and physiology of the larynx (25). Apart from compensation, after vocal fold paralysis occurs in patients who cannot achieve complete glottal closure, some structural changes also occur. Among these changes are an asymmetric bending larynx, changes in the location of the arytenoid cartilage, changes in the vocal fold tension, granuloma formation and ventricular fold hypertrophy $(26,27)$. In our patient, dysphonia emerged at a very early period. The patient had a left vocal fold paralysis and a shortened and altered inferomedial position of the fold in video laryngoscopic examination. Laryngeal EMG also performed on the patient, and a reduced neuronal activity was determined according to the counterparty. The patient did not want an invasive procedure and was followed-up with breath and voice exercise programmes.

Treatment options should be individualised according to the demographic characteristics of the patient and the severity of the deformity due to the variable clinical picture. Surgery is recommended in patients with advanced thoracic collapse, paradoxical thoracic movement, unprotected mediastinum, non-existence of breast tissue and cosmetic defects (28). In patients with a depressed thorax, the concave structure should be corrected by surgical repair, thereby ending the paradoxical movement of the chest wall. Functional problems in most patients may not bother patients very much, and patients may want to undergo surgery for cosmetic reasons (29). Surgical treatment may not be performed only in patients whose pectoral muscles are affected and with minimal abnormality. Flaps (lattisimus dorsi and rectus abdominus) can be used to repair the structural abnormality in the chest wall and provide functionality, or repairs can be made using only custom-made silicone prosthesis for cosmetic purposes (29). Latissimus dorsi muscle is frequently used in soft tissue repairs and successful results have been obtained (30). In our patient with the diagnosis of PS, no reconstructive surgery was performed because the patient's deformity was minimal and did not cause any functional impairment.

PS is a rare anomaly and other components of the syndrome need to be investigated in patients with thoracic abnormalities. This case report is the first study in the literature of PS accompanied by vocal fold paralysis. In our patient, the pathology associated with unilateral involvement is important in terms of showing that it may be associated with abnormalities of the contralateral side. Therefore, bilateral examinations performed in the investigation of anomalies in patients with PS would be useful.

\section{Ethics}

Informed Consent: Approval (informed consent) was obtained from the patient to present this case report.

Peer-review: Externally peer-reviewed.
Authorship Contributions: Surgical and Medical Practices - M.Y.; Concept - Z.A., B.M.Ş., Ö.Y.; Design - M.Y., B.M.Ş., Ö.Y.; Analysis or Interpretation M.Y., Z.A., Ö.Y.; Literature Search - B.M.S..,; Writing - M.Y., Z.A., Ö.Y.

Conflict of Interest: No conflict of interest was declared by the authors.

Financial Disclosure: The authors declared that this study received no financial support.

\section{References}

1. Yiyit N. Definition of the inclusion criteria of Poland's syndrome. Ann Thorac Surg 2014; 98: 1886

2. Seyfer AE, Fox JP, Hamilton CG. Poland syndrome: evaluation and treatment of the chest wall in 63 patients. Plast Reconstr Surg 2010; 126: 902-11.

3. Fokin AA, Robicsek F. Poland's syndrome revisited. Ann Thorac Surg 2002; 74: $2218-25$.

4. Friedman T, Reed M, Elliot AM. The carpal bones in Poland syndrome. Skeletal Radiol 2009; 38: 585-91.

5. Sharma CM, Kumar S, Meghwani MK, Agrawal RP. Poland syndrome. Indian J Hum Genet 2014; 20: 82-4.

6. Uludag M, Cece H, Incebiyik S, Demirkol A, Karakas E, Akgun K. Scapular winging in Poland syndrome. Clinics (Sao Paulo) 2011; 66: 929-30.

7. Catena N, Divizia MT, Calevo MG, Baban A, Torre M, Ravazzolo R, et al. Hand and upper limb anomalies in Poland syndrome: a new proposal of classification. J Pediatr Orthop 2012; 32: 727-31.

8. Veir Z, Dujmović A, Duduković M, Mijatović D, Cvjeticanin B, Veir M. Endoscopically assisted latissimus dorsi flap harvesting and breast reconstruction in young female with Poland syndrome. Coll Antropol 2011; 35: $1303-5$.

9. Hsieh WB, Leung C. Poland syndrome in a neonate: report of one case. Acta Paediatr Taiwan 2005; 46: 239-43.

10. Kennedy KR, Wang AL. Poland Syndrome. N Engl J Med 2018; 378: 72.

11. Dustagheer S, Basheer MH, Collins A, Hill C. Further support for the vascular aetiology of Poland syndrome--a case report. J Plast Reconstr Aesthet Surg 2009; 62: e360-1.

12. Cingel V, Bohac M, Mestanova V, Zabojnikova L, Varga I. Poland syndrome: from embryological basis to plastic surgery. Surg Radiol Anat 2013; 35: 63946

13. Perez Aznar JM, Urbano J, Garcia Laborda E, Quevedo Moreno P, Ferrer Vergara L. Breast and pectoralis muscle hypoplasia. A mild degree of Poland's syndrome. Acta Radiol 1996; 37: 759-62.

14. Sierra Santos L, González Rodríguez MP. Poland syndrome: description of two patients in the same family. An Pediatr (Barc) 2008; 69: 49-51.

15. Jeung MY, Gangi A, Gasser B, Vasilescu C, Massard G, Wihlm JM, et al. Imaging of chest wall disorders. Radiographics 1999; 19: 617-37.

16. Yiyit N, Ișıtmangil T, Öksüz S. Clinical analysis of 113 patients with Poland syndrome. Ann Thorac Surg 2015; 99: 999-1004.

17. Mojallal A, La Marca S, Shipkov C, Sinna R, Braye F. Poland syndrome and breast tumor: a case report and review of the literature. Aesthet Surg J 2012; 32: 77-83.

18. Caksen H, Patiroglu T, Ozdemir MA, Patiroglu TE, Poyrazoglu MH, Tercan M. Neuroblastoma and Poland syndrome in a 15 -year-old boy. Acta Paediatr Jpn 1997; 39: 701-4.

19. Esquembre C, Ferris J, Verdeguer A, Prieto F, Badia L, Castel V. Poland syndrome and leukaemia. Eur J Pediatr 1987; 146: 444 
20. Bothe C, López M, Quer M, León X, García J, Lop J. Aetiology and treatment of vocal fold paralysis: retrospective study of 108 patients. Acta Otorrinolaringol Esp 2014; 65: 225-30.

21. Bilici S, Yildiz M, Yigit O, Misir E. Imaging Modalities in the Etiologic Evaluation of Unilateral Vocal Fold Paralysis. J Voice 2019; 33: 813.e1-813.e5.

22. Heuer RJ, Sataloff RT, Emerich K, Rulnick R, Baroody M, Spiegel JR, et al. Unilateral recurrent laryngeal nerve paralysis: the importance of 'preoperative' voice therapy. J Voice 1997; 11: 88-94.

23. Fleischer S, Schade G, Hess MM. Office-based laryngoscopic observations of recurrent laryngeal nerve paresis and paralysis. Ann Otol Rhinol Laryngol 2005; 114: 488-93.

24. Guha K, Sabarigirish K, Singh SK, Yadav A. Role of Laryngeal Electromyography in Predicting Recovery After Vocal Fold Paralysis. Indian J Otolaryngol Head Neck Surg 2014; 66: 394-7.

25. Bielamowicz S, Stager SV. Diagnosis of unilateral recurrent laryngeal nerve paralysis: laryngeal electromyography, subjective rating scales, acoustic and aerodynamic measures. Laryngoscope 2006; 116: 359-64.
26. Pinho SM, Pontes PA, Gadelha ME, Biasi N. Vestibular vocal fold behavior during phonation in unilateral vocal fold paralysis. J Voice 1999; 13: 36-42.

27. Morrison MD, Rammage LA. Muscle misuse voice disorders: description and classification. Acta Otolaryngol 1993; 113: 428-34.

28. Romanini MV, Torre M, Santi P, Dova L, Valle M, Martinoli C, et al. Proposal of the TBN Classification of Thoracic Anomalies and Treatment Algorithm for Poland Syndrome. Plast Reconstr Surg 2016; 138: 50-8.

29. Romanini MV, Calevo MG, Puliti A, Vaccari C, Valle M, Senes F, et al. Poland syndrome: A proposed classification system and perspectives on diagnosis and treatment. Semin Pediatr Surg 2018; 27: 189-99.

30. Liu C, Luan J, Ouyang Y, Zhuang Y, Xu B, Chen L, et al. Breast Reconstruction in Poland Syndrome Patients with Latissimus Dorsi Myo Flap and Implant: An Efficient Endoscopic Approach Using Single Transverse Axillary Incision. Aesthetic Plast Surg 2019; 43: 1186-94. 